\title{
THE IMPACTS OF THE INVESTMENTS IN AGRICULTURE ON ECONOMIC GROWTH IN RURAL COMMUNITIES IN ROMANIA
}

\author{
Ionut Laurentiu Petre ${ }^{1}$, Raluca Andreea Ion², \\ *Corresponding author E-mail: laurpetre15@gmail.com
}

\begin{abstract}
A R T I C LE IN F O
A B S T R A C T

Original Article

Received: 02 July 2019

Accepted: 19 August 2019

doi:10.5937/ekoPolj1904955L

UDC 330.322:631(498)

UDC 330.34:631.111(498)

Keywords:

agricultural output; GDP; investments; rural development

JEL: Q13, Q14

This paper seeks to analyze the impact of agricultural investments on economic growth in rural communities in Romania. It answers the question: are the investments in agriculture a determinant of economic growth in rural communities, and if yes, what is their impact on economic growth? The objectives are to identify, through linear regression models, the intensity and meaning of the relationships between the value of investments and the main indicators that can express economic growth in rural areas. In this purpose, the level of relationships between the value of investments in agriculture and the value of GDP in predominantly rural areas, the value of GDP in agriculture and the value of the agricultural production are analyzed. The main results show that the variables chosen are influenced by the value of the investments in different proportions, so the hypothesis that investment in agriculture has a positive and medium impact on rural economic growth is true. The most significant relationship is obtained between the value of agricultural investments and the value of agricultural production.
\end{abstract}

(C) 2019 EA. All rights reserved.

\section{Introduction}

The rural space in Romania holds significant shares of area and population: 67.8 per cent of the total territory and 53.8 per cent of the total population (European Commission, 2017). Accordingly, a special attention is given to the development of rural areas and considerable funds are oriented to finance investments in rural space.

The rural development in Romania subscribes to the rural development policy of the European Union. Known as the second pillar of the Common Agricultural Policy, the rural development policy comes to complement the market measures and financial allocations through direct payments. The European Union's rural development policy

1 Ionut Laurentiu PETRE, PhD Student, Bucharest University of Economic Studies, 6 Piata Romana, 1st district, Bucharest, 010374 Romania, +40213191900, laurpetre15@gmail. com, ORCID ID (https://orcid.org/0000-0002-2360-6844)

2 Raluca Andreea ION, Associate Professor, PhD., Bucharest University of Economic Studies, 6 Piata Romana, 1st district, Bucharest, 010374 Romania, +40213191900, raluca. ion@eam.ase.ro, ORCID ID (https://orcid.org/0000-0001-7182-5809)

http://ea.bg.ac.rs 
is funded through the European Agricultural Fund for Rural Development, worth $€ 100$ billion from 2014 to 2020. The financial allocation for Romania, for the same period, is $€ 8128$ million (European Commission, 2015).

The rural development is assessed using a set of indicators, reported annually in the European Commission publication: Rural Development in the EU - Statistical and Economic Information. Since 2014, this report has been replaced by the annual CAP context indicator. It comprises numerous indicators, among them, the socio-economic ones show the economic situation in rural areas. The GDP per capita reached $€ 29,100$ in terms of Purchasing Power Standards (PPS), as shows the latest report (European Commission, 2017). Over the period 2012-2014, rural areas had on average the lowest level of GDP per capita (72.9 per cent of the EU-28 average). Urban regions had the highest rate (120.8 per cent of the EU average).

In 2016, the GDP per capita was $€ 8,600$ in Romania, $€ 5,122$ in rural areas and $€ 16,170$ in urban areas. The difference of $€ 7,570$ indicates the socio-economic gaps between urban and rural. The improved economic situation in urban areas explains their attractiveness for population willing to live and work in urban areas. Thus, the population density in urban areas is 415.9 inhabitants $/ \mathrm{km} 2$, while in rural areas it is 68.7 inhabitants $/ \mathrm{km} 2$.

The labor productivity is lower in rural areas, $€ 10,761$, as compared to urban areas, $€ 28,917$. On average, the labor productivity in Romania is $€ 18,015$, three times lower than the average of the European Union $€ 57,417$.

Considering the socio-economic situation in rural areas, the questions arising are: what are the determinants of the rural development? Are the investments in agriculture a determinant of economic growth in rural communities, and if yes, what is their impact on economic growth?

The objective of this piece of research is to establish whether there is a relationship between investment in agriculture and economic growth in rural communities, bearing in mind that agriculture is the main economic activity in rural areas.

In pursuing this, the data corresponding to investments in agriculture and those corresponding to economic growth, GDP in predominantly rural regions, GDP in agriculture and the value of agricultural production, have been retrieved from the National Institute of Statistics of Romania database and Eurostat. The data were analyzed using SPSS program, and the models resulted express the relationships between investments and economic growth.

The paper is organized as follows. In Section 2, a brief of literature review is presented in order to establish the study hypothesis in Section 3. Section 4 gives an overview on the data and the methodology used to analyze the relationship between investments and economic growth. In Section 5, the findings are presented and discussed. Finally, in Section 6, conclusions are drawn and their implications are outlined. 


\section{Literature review}

There is abundant literature on the impact of investments on economic growth. Benfica et al. (2018) analyzed the links between agricultural investment and the growth or poverty of the Mozambican economy. They have carried out econometric analyses at both household and national level on the impact of investment on farm productivity and growth. At a macroeconomic level, Mozambique's agricultural investment plan aimed at increasing the share of resources allocated for irrigation and subsidies, and the author's research concluded that the extension of agriculture is not based only on these two elements, so it can be explained the rather modest accelerations of economic growth and poverty reduction. The authors recommend higher priority and increased efficiency of public investment to develop economic growth.

On a similar theme, the impact of investment, Dillon et al. (2011) estimated this impact of rural investment in Nepal, realizing a "quantitative assessment of the impact of access to rural road, irrigation, and extension services" in Nepal. The author claims that "future planning and more efficient resource allocation can help improve rural welfare". To quantify the impact of rural investment, different methodologies have been used, so rural investment has an effect on improving household welfare, being quantified by land value, increasing consumption, reducing poverty or increasing farm incomes.

An impact analysis has been also proposed by Aït-Youcef (2018), who estimated the influence of investment indices on commodities. The author stated that it is essential to identify the financing channel for agricultural products to understand the dynamics of agricultural prices. At the same time, the author admits the links between capital and agriculture and the interactions between them. "This study highlights a reinforcement of the integration between agricultural commodities and equity indices when agricultural returns are remarkably extreme". The author believes that research into how agricultural product financing affects the development of poverty in developing countries needs to be explored.

It should also be noted that investments in the agricultural sector are also influenced by economic situation. For example, Tamasila et al. (2018) tested through a research the relationship between the cash flow and the investment decision of the companies in the agricultural sector in Romania. The authors investigated the relationship between investment and cash flow for 739 Romanian companies operating in the agricultural sector, considering this connection quite controversial. Authors' research shows that the level of investment is in a bidirectional causal relationship with cash flow, but when considering the dynamics of the investment, the causal link is less significant. Thus, the main conclusion is that the importance of cash flow is significant in supporting shortterm investments, which is favorable for the agricultural sector.

Another external factor that can influence investment is studied in the paper of Nolte et al. (2017), analyzing the employment effects of large-scale agricultural investment. The authors have assumed that "the largest generation of direct net employment is expected for investments that do not entail massive crowding out of former income-generating activities and cultivate labor-intensive crops under contract farming schemes", but this 
scenario applies to a reduced share of purchased land. "This implies that crowding out of former smallholder farmers is a serious issue. We find a massive loss of employment, with the highest losses stemming from the cultivation of capital-intensive crops". The authors believe that "the employment effects of LSAIs depend on the specific project".

A fairly controversial topic is foreign direct investment, and in the literature there are quite varied opinions about the influence of these investments on economic growth. An approach in this respect was made by Maizura Abdul Rashind et al. (2016) when examining the determinants of foreign direct investment in the agricultural sector, based on economies in OIC countries. For this, five factors have been chosen that could influence foreign direct investments, namely market size, inflation, poverty, exchange rate and infrastructure index. These variables have been statistically correlated with the dependent variable (foreign direct investment) and the authors' main conclusions refer to the decision-makers that should focus and pay attention to all the determinants, especially with regard to poverty reduction and the size of the market in the agricultural sector. These two determinants were the most important in terms of their influence on foreign direct investment in the agricultural sector in OIC countries.

In the same sense, Antoci et al. (2015) explored the effects of external investment inflows on the development of local rural economies, given two constraints, segmentation of the capital market and environmental externalities. The author asserts that external investment can be a crucial incentive for the local economy by increasing existing capital, directly through new, revenue-generating investments, but also indirectly through the possible reinvestment in the local sector of higher wages earned by new local employees in the new sector. Foreign investment may degrade the local environment, but new activities can compensate by reducing the productivity of the primary sector. The author finds a direct link between external investment and the welfare of the local population.

On the other hand, in the literature, there are also slightly different views on how foreign direct investment affects economic growth. Thus, Alvarado et al. (2017) examined the effect of foreign direct investment on economic growth in 19 Latin American countries. Using econometrics, it has been shown that the foreign direct investment effect on economic growth is not statistically significant in aggregate form. Foreign direct investments have a positive and significant effect on the product in high-income countries. The results of the authors' research show that foreign direct investments are not an appropriate mechanism for accelerating economic growth in Latin America, with the exception of high income countries.

Makiela et al. (2018) found a similar idea, namely, that foreign direct investments conclusively affected economic development through the accumulation of inputs, but not the channel of factor productivity growth, respectively research results suggest that other factors, in addition to foreign direct investment, would have helped to increase productivity in developing countries.

The results of the research by Iamsiraroj et al. (2015) suggest that, while foreign direct investment is increasing, the full benefits of foreign direct investments may 
not be realized in the absence of well-functioning financial markets and higher levels of international trade. However, Iamsiraroj (2016) also investigated the associations between foreign direct investments and income growth per capita, using simultaneously a system of equations in 124 transnational data. The results of the estimate indicate that the overall effects of foreign direct investments are positively associated with higher rates of growth and vice versa.

Considering all the arguments above, our intention in this paper is to investigate the relationship between investments and economic growth in rural areas in Romania, by analyzing the correlations between the values of investments and the values of GDP in agriculture and GDP in predominant rural areas.

\section{Study hypothesis}

The results of previous research described above drive to the need of answering the question: Are the investments in agriculture a determinant of economic growth in rural communities, and if yes, what is their impact on economic growth? This piece of research starts from the premise that investments are a vector of rural development and, as such, contribute to the economic growth. The hypothesis tested is:

$\mathrm{H} 1$ : Investments in agriculture have a positive and medium impact on economic growth in rural areas.

The hypothesis is sustained by other researchers Adams (2009), Belloumi and Alshehry (2018), showing that investments are positive and significantly correlated with economic growth. Alvarado (et al. 2017) argued that foreign direct investment has a positive and significant effect on product in high-income countries, while in upper-middle-income countries the effect is uneven and non-significant. Rashid (et al. 2016) found that the agriculture sectors react as important keys in the expansion of any economy growth to eliminate the poverty issues. Tamasila (et al. 2017) showed that investment in fixed assets in agriculture enhances the cash flow level for the subsequent period.

\section{Data and Methodology}

The investigation of the relationship between GDP and direct investments is based on the model of growth where economic output (GDP) is determined by the economic input (investments). For analyzing the direction and the intensity of this relationship, one variable has been considered for the input - the value of investment in agriculture, and three variables have been considered for the agricultural output - GDP in predominantly rural areas, GDP in agriculture, and the value of agricultural production.

The data have been retrieved from the National Institute of Statistics of Romania and they refer to the period 1998-2015. The data referring to the GDP in predominant rural areas have been retrieved from Eurostat. The dynamic indices of the values of investments, GDP in agriculture, GDP in predominantly rural areas and the value of the agricultural production are presented in Figure 1. 
Figure 1. The dynamic indices of investments in agriculture, GDP in agriculture, GDP in predominantly rural areas and the value of the agricultural production, in Romania, 1998-2015

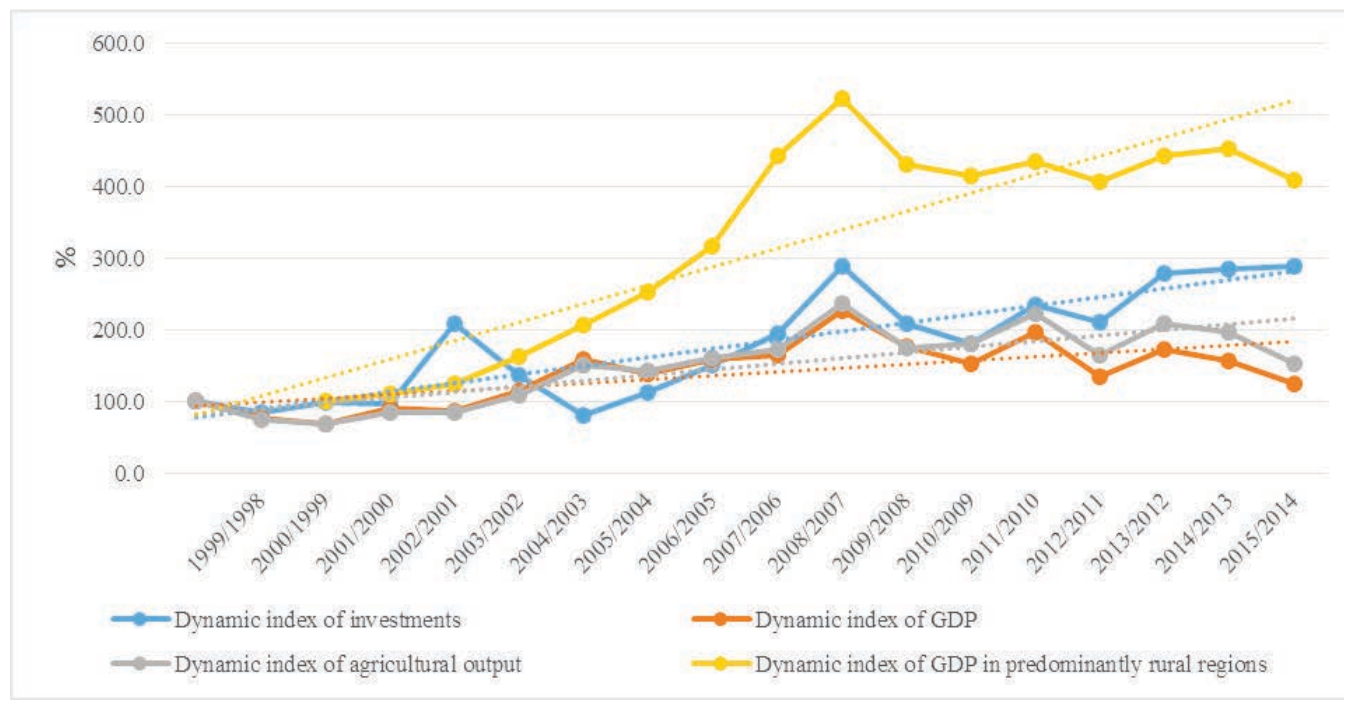

Source: own calculations based on data from the National Institute of Statistics of Romania and Eurostat

The trends of all indicators show increases of their values. Significant amounts of money have been allocated to agriculture from 2008 forward, after Romania accession to the European Union. The year 2007 opened new financial opportunities and allocations through National Program for Rural Development. The value of investments in agriculture increased three times in 2008 compared to 2007, achieving \$1,330 million. Significant growths registered in the period 2013-2015, where the values of investments increased 2.8 times as compared to the previous year, and the investments reached, anew, the value of $\$ 1,330$ million.

The values of the agricultural production, GDP in agriculture and GDP in predominantly rural areas increased over the period under analysis. They reached a peak in 2008, when the GDP in agriculture registered $\$ 13,557$ million, 2.2 times higher as compared to the previous year, and the value of production reached \$26.3 million, 2.3 times higher than its value in 2007. The GDP in predominantly rural areas constantly increased and reached the highest value of $\$ 84,300$ million, in 2008 .

\section{Results}

The variables used to investigate the relationship between investments and economic growth have been analyzed using SPSS 22. The results of the regression models are presented in Table 1 and Figure 2. The graphs in Figure 2 show linear correlations between the variables. The models are statistically significant since the values of Sig. are below .05. Significant correlations have been found between the value of investments in agriculture and GDP in predominantly rural regions $(\mathrm{R} 2=.615)$ and between the value 
of investments and the value of the agricultural production $(\mathrm{R} 2=.545)$, and weaker correlation between the value of investments and GDP in agriculture $(\mathrm{R} 2=.365)$. It means that the level of GDP in agriculture is influenced by other significant factors out of investments - the agricultural land potential, the labor etc.

Table 1. The influence of investments on the values of GDP in predominantly rural regions, GDP in agriculture, and the value of the agricultural production

\begin{tabular}{|l|r|r|r|}
\hline \multicolumn{1}{|c|}{ Variable } & $\begin{array}{c}\text { Coefficients of } \\
\text { correlation } \\
\text { (R Square) }\end{array}$ & $\begin{array}{c}\text { Coefficients of } \\
\text { regression function }\end{array}$ & \multicolumn{1}{c|}{ Sig. } \\
\hline GDP in predominantly rural regions & .615 & .784 & .000 \\
\hline GDP in agriculture & .365 & .604 & .008 \\
\hline Value of the agricultural production & .545 & .738 & .000 \\
\hline
\end{tabular}

Source: Results of the regression model

Figure 2. The correlations between investments and the values of GDP in predominantly rural regions (a), GDP in agriculture (b), and the value of the agricultural production (c)

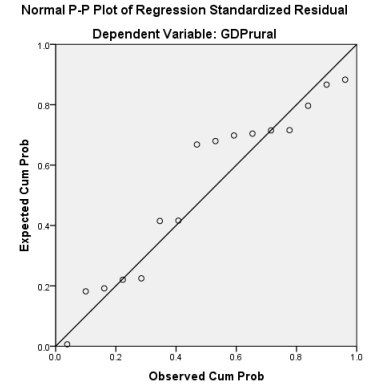

(a)

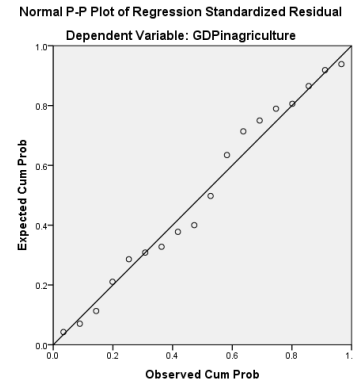

(b)

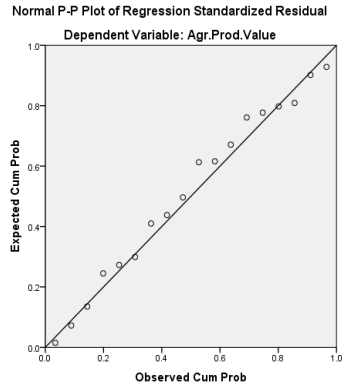

(c)

Source: Results of the regression model

The relationships between investments and GDP in predominantly rural regions are analysed using the simple regression model. The results are presented in Table 1 . The coefficient of correlation between investments and GDP in predominantly rural regions is .615 , showing a medium and direct relation between the two variables. The model which shows the relationships between investments and GDP in predominantly rural regions is: $y=0.784 x$, meaning that a change by one unit in the level of investments leads to a change with 0.784 of the GDP in predominantly rural areas. The values of Sig.is .000 , below .05 , meaning that the model is valid. The interval for B value do not contain the value 0 , meaning, again, that the model is valid. The results are provided with a standard error of 11.5. The high level of the standard error is a limit of the research.

The relationships between investments and GDP in agriculture are presented in Table 1. The coefficient of correlation between investments and GDP in agriculture is .365, showing a weak and direct relation between the two variables. The function which shows the relationships between investments and GDP in agriculture is: $y=0.604 x$, 
meaning that a change by one unit in the level of investments leads to a change with 0.604 of the GDP in agriculture. The values of Sig.is .008, below .05 and the interval for $\mathrm{B}$ value do not contain the value 0 , meaning that the model is valid. The results are provided with a standard error of 1.49 . The high level of the standard error is a limit of the research.

The relationships between investments and the value of the agricultural production are analysed using the simple regression model. The results are presented in Table 1. The coefficient of correlation between investments and the value of the agricultural production is .545 , showing a medium and direct relation between the two variables. The model which shows the relationships between investments and the value of the agricultural production is: $\mathrm{y}=0.738 \mathrm{x}$, meaning that a change by one unit in the level of investments leads to a change with 0.738 of the value of the agricultural production. The values of Sig. is .000 , below .05 and the interval for $B$ value do not contain the value 0 , meaning that the model is valid. The results are provided with a standard error of .003 .

\section{Conclusions}

It was found that investments in agriculture impact the levels of the GDP in predominantly rural regions, GDP in agriculture, and the level of the agricultural production. The hypothesis "Investments in agriculture have a positive and medium impact on economic growth in rural areas" is confirmed and a final answer to the research question is that investments in agriculture represent a determinant of economic growth in rural communities.

Among the models analyzed, the relationship between the level of investments in agriculture and the value of the agricultural production is the most significant. The results of the regression model show that investments influence the value of the agricultural production, with an impact of .738, meaning that an increase of one US\$ in the level of investment leads to a growth of US\$ 0.738 in the level of the agricultural production.

The results of this research are expected to provide policy makers with insight into the determinants of the economic growth in rural areas and the findings may be used to develop policy initiatives to finance investments in agricultural activity for the wider development of the rural regions.

\section{Conflict of interests}

The authors declare no conflict of interest.

\section{References}

1. Adams, S. (2009). Foreign Direct investment, domestic investment, and economic growth in Sub-Saharan Africa. Journal of Policy Modeling, 31, 939-949

2. Aït-Youcef, C. (2019). How index investment impacts commodities: A story about the financialization of agricultural commodities, Economic Modelling, 80, 23-33 
3. Alvarado, R., Iñiguez, M., \& Ponce, P. (2017). Foreign direct investment and economic growth in Latin America, Economic Analysis and Policy, 56, 176-187.

4. Antoci, A., Borghesi, S., Russu, P., \& Ticci, E. (2015). Foreign direct investments, environmental externalities and capital segmentation in a rural economy, Ecological Economics, 116, 341-353.

5. Belloumi, M., \& Alshehry, Atef. (2018). The Impacts of Domestic and Foreign Direct Investments on Economic Growth in Saudi Arabia. Economies, 6, 1-17

6. Benfica, R. (2019). Linking agricultural investments to growth and poverty: An economywide approach applied to Mozambique, Agricultural Systems, 172, 91100

7. Dillon A., Sharma M., \& Zhang X. (2011). Estimating the impact of rural investments in Nepal, Food Policy, 36, 250-258.

8. European Commission, (2015). Commission Delegated Regulation (EU) No.2015/791 amending Annex I to Regulation (EU) 1305/2013 of the European Parliament and of the Council on support for Rural Development. Retrieved from: https:/ec.europa.eu/agriculture/sites/agriculture/files/ruraldevelopment-2014-2020/country-files/common/funding-per-ms en.pdf

9. European Commission, (2017). CAP context indicators - 2017. https://ec.europa. eu/agriculture/cap-indicators/context/2017 en

10. Iamsiraroj, S. (2016). The foreign direct investment-economic growth nexus, International Review of Economics and Finance, 42, 116-133,

11. Iamsiraroj, S. Ulubaşoğlu M.A. (2015). Foreign direct investment and economic growth: A real relationship or wishful thinking? Economic Modelling, 51, 200-213,

12. Intan Maizura Abdul Rashida, Nor'aznin Abu Bakar, \& Nor Azam Abdul Razak. (2016). Determinants of Foreign Direct Investment (FDI) in Agriculture Sector Based on Selected Highincome Developing Economies in OIC Countries: An Empirical Study on the Provincial Panel Data by Using Stata, 2003-2012, Economics and Finance, 39, 328 - 334

13. Leight J. (2016). Reallocating wealth? Insecure property rights and agricultural investment in rural China, China Economic Review, 40, 207-227

14. Makiela, K., \& Ouattara, B. (2018). Foreign direct investment and economic growth: Exploring the transmission channels, Economic Modelling, 72, 296-305

15. Nolte, K., \& Ostermeier, M. (2017). Labour Market Effects of Large-Scale Agricultural Investment: Conceptual Considerations and Estimated Employment Effects, World Development, 98, 430-446

16. Tămăsilă M., Miclea S., Vartolomei M., Pascu D., \& Albulescu C.T. (2018). Cash flow and investment decision: an application on the Romanian agriculture sector, Social and Behavioral Sciences, 238, $704-713$ 
